\title{
Molecular Mapping of Genes and QTLs in Pigeonpea
}

\author{
Reyazul Rouf Mir, Irshad Ahmad Rather, \\ Mohd Ashraf Bhat, G.A. Parray and Rajeev K. Varshney
}

\begin{abstract}
Pigeonpea is one of the most important grain legume crops grown in arid and semiarid regions of the world. There is an increasing demand for the development of new cultivars with high yield potential and better adaptability to adverse environmental conditions. Recent advances in genomics tools and techniques have helped to develop large repertoire of molecular markers and genotypic platforms. The availability of molecular markers facilitated the development of high-density genetic maps that have been used in discovery of important/major QTLs for targeted traits in pigeonpea. In addition, the availability of high-throughput genotypic platforms helped to generate whole genome genotypic data in high-throughput manner necessary for whole genome scanning/ genome-wide association mapping of economically important traits. The advances in comparative genomics, transcriptomics, and whole genome sequencing have uncovered thousands of useful genes including some genes unique to pigeonpea crop. The availability of wealth of genomics resources/information will facilitate molecular breeding aimed at improving production and productivity of pigeonpea in extreme environments of arid and semiarid regions of the world.
\end{abstract}

R.R. Mir $(\bowtie)$ · I.A. Rather · M.A. Bhat

G.A. Parray

Division of Plant Breeding and Genetics,

Sher-e-Kashmir University of Agricultural Sciences

\& Technology of Kashmir (SKUAST-K), Kashmir

180009, India

e-mail: imrouf2006@gmail.com

R.K. Varshney

International Crops Research Institute for the

Semi-Arid Tropics (ICRISAT),

Patancheru 502324, India 


\subsection{Introduction}

Pigeonpea (Cajanus cajan L. Millsp.) is one of the major grain legume crops of the arid and semiarid regions of the world and the second most important pulse crop in India. It is cultivated in many parts of the world like China, Kenya, Myanmar, Nepal (Smartt 1990), but its primary origin and diversification center is India (Vavilov 1928; Van Der Maesen 1990). Globally, pigeonpea is grown on $\sim 5$ million hectares (ha) and India accounts for over $85 \%$ of the global area (Saxena et al. 2015). Pigeonpea is a diploid crop with $2 \mathrm{n}=2 \mathrm{x}=22$ and having a genome size of 833.1 Mbp (Varshney et al. 2012a). This crop has great nutritional as well as economic value especially for poor people living in Asia, Africa, South America, Central America, and the Caribbean (Mula and Saxena 2010). Almost all parts of this crop are consumed for variety of purposes like pigeonpea seeds having $20-22 \%$ protein are consumed as green peas, whole grain, or split peas, the seed and pod husks make a quality feed, whereas dry branches and stems serve as domestic fuel, fallen leaves from the plant provide vital nutrients to the soil, and the plant also enriches soil through symbiotic nitrogen fixation (Varshney et al. 2010a, 2010b; Saxena et al. 2010a, b; Mohar et al. 2014)

Pigeonpea withstands elevated temperatures and water scarcity and that adds to its importance as a crop of choice in arid and semiarid tropical (SAT) regions of the world. Despite its importance in the SAT regions and extensive efforts of research community, little improvement has been made in increasing pigeonpea production. Its production is mostly hindered by a variety of biotic (diseases and insect pests) and abiotic (drought, salinity, and waterlogging) stresses (Varshney et al. 2010a, b). Fusarium wilt (FW) and sterility mosaic disease (SMD) are the major biotic constraints limiting pigeonpea production.

In order to address above production constraints in pigeonpea, genomics tools like molecular markers, genetic/trait mapping, and genome sequencing are the prerequisites for pigeonpea improvement. However, in the past, development of pigeonpea genetic maps has been hindered by low level of genetic diversity present within the gene pool and less availability of DNA-based molecular markers. Little was done in terms of discovery of genes for important targeted traits. This paucity in gene discovery programs in pigeonpea was partly attributed to its 'orphan crop' status few years back. During the last decade, ICRISAT along with its national/international partners has developed significant genomic resources of pigeonpea that is impacting/will impact on trait mapping and molecular breeding of this crop. Therefore, recent advances in genomics tools and technologies like advances in sequencing and genotyping technologies have made this crop as one of the resource-rich legume crops. As a result, large repertoire of molecular markers, genotyping platforms, transcriptomics resources, and more recently draft genome sequence have been developed/became available in this crop (Varshney et al. 2012a, b).

In terms of molecular markers, large sets of simple sequence repeat (SSR) markers (Saxena et al. 2010a, b; Bohra et al. 2011; Dutta et al. 2011), diversity array technology (DArT) markers (Yang et al. 2006, 2011), single feature polymorphism (SFP) markers (Saxena et al. 2011), and single nucleotide polymorphism (SNP) genotyping platforms (see Varshney et al. 2012b; Saxena et al. 2014) have been developed. In addition, molecular markers have been used for the development of low-, moderate-, and high-density genetic maps in pigeonpea. For instance, a moderate-density interspecific genetic map is already available (Bohra et al. 2011) and a less dense genetic map for cultivated pigeonpea has been also developed (Gnanesh et al. 2011). More recently, four genetic maps and subsequent first consensus/integrated genetic map based on six $\mathrm{F}_{2}$ intraspecific mapping populations were also developed in pigeonpea (Bohra et al. 2012). These molecular markers and molecular marker-based genetic maps that have become available/been developed in pigeonpea provide great opportunities to discover genes/QTLs responsible for important targeted traits in 
pigeonpea. The discovery of genes once done will facilitate molecular breeding aimed at improving pigeonpea against a range of stresses, quality, etc. Some studies have been already conducted, where these genetic maps have helped in discovery of quantitative trait loci (QTLs)/genes for some of the important traits like sterility mosaic disease (SMD) (Gnanesh et al. 2011) and fertility restoration (FR) (Bohra et al. 2012).

Another very important approach that does not involve development and use of genetic maps from biparental mapping populations for gene discovery is 'association mapping.' Association mapping is considered one of the most important approaches of gene discovery that overcomes several limitations of QTL mapping (for details, see Mir et al. 2012 for a review). This approach has been already used in pigeonpea by scanning whole genome of pigeonpea through Illumina, GoldenGate SNP, and DArT markers, followed by discovery of genes/significantly associated markers linked with determinacy trait in pigeonpea (Mir et al. 2013). Similarly, in another study, whole genome association mapping (using DArT markers) has been also used for identification of marker-trait associations for growth, phonological and yield/yield contributing traits in pigeonpea (Rajeev Varshney, personal communication). In addition to marker-based QTL mapping and association mapping, candidate gene-based association mapping has been also used to identify candidate genes responsible for determinacy trait in pigeonpea. In this chapter, efforts have been made to summarize all the available results on discovery of gene/QTLs through different approaches in pigeon pea. We have also made efforts to summarize results on discovery/identification of genes through transcriptomics/next-generation sequencing approaches in pigeonpea.

\subsection{Approaches for Identification and Mapping of Genes and QTLs in Pigeonpea}

Several approaches are available and have been used to identify genes and QTLs in pigeonpea (Fig. 6.1). However, the progress of mapping of genes and QTLs in pigeonpea is still at its early stage when compared to other grain legume crops like soybean, chickpea, pea, common bean, and groundnut. Therefore, concerted efforts need to be made to map genes for important agronomic traits in this crop. The genes once mapped could be useful for improving production and productivity of pigeonpea in arid and semiarid regions of the world. For mapping of QTLs, two important approaches like QTL mapping and association mapping have been extensively used in all crops including pigeonpea. The identification of QTLs mainly relied on linkage analysis involving use of biparental mapping populations. This method is more common and proved successful for identification of QTLs for variety of traits in different crops worldwide. However, QTL mapping has several disadvantages including possessing low resolution (see Mir et al. 2012; Gupta et al. 2013). To overcome most of the disadvantages associated with QTL mapping, linkage disequilibriumbased association mapping (AM) has provided alternative strategy to identify marker-trait associations (MTAs). Association mapping has number of advantages over other mapping techniques including the potential for increased QTL resolution, and an increased sampling of molecular variation (for reviews, see Buckler and Thornsberry 2002; Flint-Garcia et al. 2003; Gupta et al. 2005; Yu and Buckler 2006; Mir et al. 2012). In addition to QTL mapping and association mapping for mapping genes and QTLs, more direct methods like transcriptomics, candidate gene analysis/sequencing, and genome sequencing 
have been preferred method for gene discovery nowadays. The progress made in discovery of genes through various approaches in pigeonpea will be discussed below.

\subsection{Identification/Mapping of Genes Through QTL Mapping and Association Mapping}

As mentioned earlier, not many studies have been conducted for discovery of QTLs through either QTL mapping or association mapping. Few studies that involve identification of QTLs through QTL mapping/association mapping in pigeon pea are summarized in Table 6.1. The important traits that have been targeted in these few studies included plant height, number of branches, pod number, flowering time, determinacy, fertility restoration (FR), Fusarium wilt (FW), and sterility mosaic disease (SMD) (Table 6.1). However, among these traits, most important targeted traits receiving more attention are biotic stresses like FW and SMD. For instance, several RAPD, SCAR, and SSR markers have been reported to be associated with FW in some earlier studies (Kotresh et al. 2006; Prasanthi et al. 2009; Singh et al. 2013). Similarly for SMD, Gnanesh et al. (2011) identified six (06) QTLs in two different populations and for two different SMD isolates. Among these six (06) QTLs, one QTL (qSMD4) on LG07 explaining $24.72 \%$ phenotypic variation for SMD is considered major/important QTL. This major QTL may prove useful in marker-assisted selection (MAS) programs after its validation. For FR, four (04) QTLs/genomic regions including two major QTLs (explaining $>20 \%$ phenotypic variation) were identified from three different

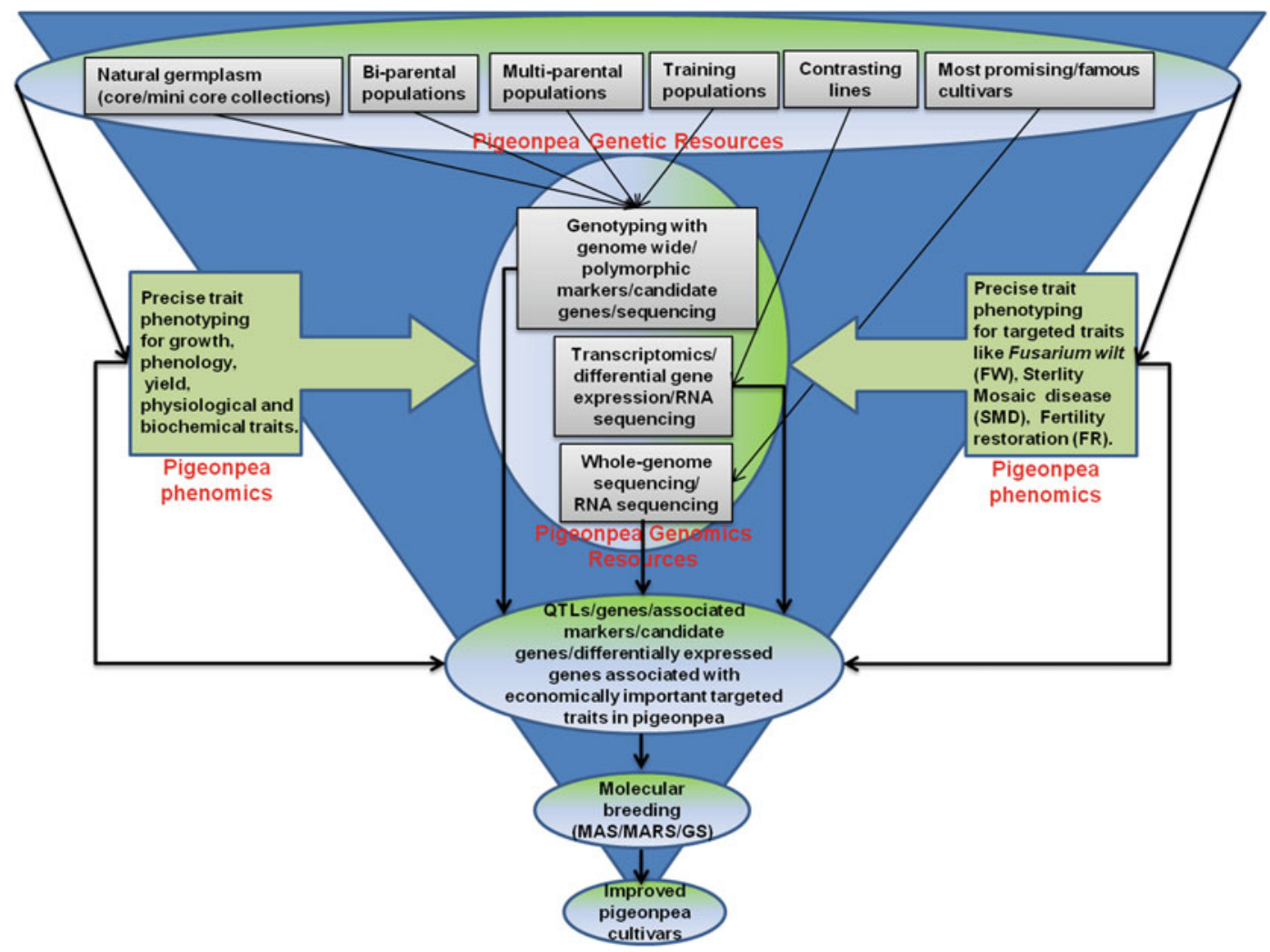

Fig. 6.1 Different steps involved in discovery/mapping of genes/QTLs for different traits and their use for development of improved pigeonpea cultivars 
Table 6.1 QTLs identified through QTL mapping and association mapping in pigeon pea

\begin{tabular}{|c|c|c|c|}
\hline Trait & Name/number of QTL/marker identified & Linkage group (LG) & References \\
\hline Plant height & qPH4.1 ${ }^{\mathrm{a}}, q P H 5.1$ & LG_Cc4, LG_Cc5 & \multirow{6}{*}{$\begin{array}{l}\text { Kumawat et al. } \\
\text { (2012) }\end{array}$} \\
\hline $\begin{array}{l}\text { Primary } \\
\text { branching }\end{array}$ & $q P B 4.1^{\mathrm{a}}, q P B 5.1$ & LG_Cc4, LG_Cc5 & \\
\hline $\begin{array}{l}\text { Secondary } \\
\text { branching }\end{array}$ & $q S B 5.1$ & LG_Cc5 & \\
\hline Number of pods & $q P D 3.1, q P D 4.1, q P D 5.1^{\mathrm{a}}$ & $\begin{array}{l}\text { LG_Cc3, LG_Cc4, } \\
\text { LG_Cc5 }\end{array}$ & \\
\hline Flowering & $q F L 4.1^{\mathrm{a}}, q F L 5.1$ & LG_Cc4, LG_Cc5 & \\
\hline Maturity & $q M T 4.1, q M T 5.1^{\mathrm{a}}, q M T 10.1$ & $\begin{array}{l}\text { LG_Cc4, LG_Cc5, } \\
\text { LG_Cc10, }\end{array}$ & \\
\hline $\begin{array}{l}\text { Fertility } \\
\text { restoration }\end{array}$ & $\begin{array}{l}\text { QTL-RF-1, QTL-RF-2, QTL-RF-3, } \\
\text { QTL-RF-4 }^{\text {a }}\end{array}$ & $\begin{array}{l}\text { LG06, LG11, } \\
\text { LG06, LG06 }\end{array}$ & Bohra et al. (2012) \\
\hline SMD resistance & qSMD4 & LG07 & $\begin{array}{l}\text { Gnanesh et al. } \\
(2011)\end{array}$ \\
\hline Determinacy & Six DArT and 19 SNP markers & NA & Mir et al. (2013) \\
\hline
\end{tabular}

The QTL with highest $\mathrm{R}^{2}$ value has been highlighted with ' $\mathrm{a}$ '

genetic backgrounds/mapping populations. These QTLs were designated as QTL-RF-1, QTL-RF-2, QTL-RF-3, and QTL-RF-4 explaining phenotypic variation of $14.85,15.84,20.89$, and $24.17 \%$, respectively (Bohra et al. 2012). For plant height, number of branches, pod number, and flowering time, a total of 13 QTLs were identified (Table 6.1). The phenotypic variation explained (PVE\%) by these individual QTLs ranged from 3.18 to $51.4 \%$ (Kumawat et al. 2012). Similarly for determinacy, six DArT (among 6144 features) and 19 SNPs (among 768 SNPs) have been found significantly associated with determinacy trait in collection of 94 diverse pigeonpea germplasm lines comprising both determinate (11) and indeterminate (83) lines (Mir et al. 2013).

In addition to QTL mapping and association mapping, sometimes advanced backcross-QTL (AB-QTL) mapping initially proposed by Tanksley and Nelson (1996) has been found promising for simultaneous discovery and transfer of QTLs. In pigeonpea, $\mathrm{AB}-\mathrm{QTL}$ mapping projects were also started by a team of scientists led by Dr. Rajeev Varshney and Nallini Malikarjuna of ICRISAT, Hyderabad, by developing four different mapping populations involving C. cajanifolius and $C$. acutifolius species for agronomically important traits. The mapping populations have been genotyped using DArT markers and are being phenotyped for different traits for their use in identification of MTAs (Rajeev Varshney, personal communication).

\subsection{Candidate Gene Analysis/ Identification/Mapping in Pigeonpea}

Biotic and abiotic stresses cause huge losses in the production of pigeonpea. Among the biotic stresses, FW and SMD are the two major constraints in crop production (Sharma et al. 2012). Several candidate genes have been already identified and mapped for different traits using different plant material/types of populations. The process of candidate gene identification/mapping will be accelerate due to the availability of pigeonpea draft genome sequence assembly. Different approaches like comparative genomics, translational genomics, differential gene expression (qRT-PCR), overexpression, NGS-based approaches, genetic/QTL mapping have been used to identify and map candidate genes in pigeonpea (Table 6.2). For instance, two important genes C.cajan_01839 and C.cajan_03203 have been identified for resistance to SMD and FW, 
Table 6.2 Candidate genes identified/mapped in pigeonpea

\begin{tabular}{l|l|l|l}
\hline Gene & Trait & Approach & References \\
\hline CcHyPRP & Drought & Overexpression & $\begin{array}{l}\text { Priyanka et al. } \\
(2010)\end{array}$ \\
\hline CcCYP & $\begin{array}{l}\text { Drought, salinity, and extreme } \\
\text { temperatures }\end{array}$ & Overexpression & $\begin{array}{l}\text { Sekhar et al. } \\
(2010)\end{array}$ \\
\hline$C c M T 1$ & Heavy metal stress & Overexpression & $\begin{array}{l}\text { Sekhar et al. } \\
(2010)\end{array}$ \\
\hline$C c C D R$ & Drought, salinity, and cold & Homology & $\begin{array}{l}\text { Tamirisa et al. } \\
(2014)\end{array}$ \\
\hline$C c T F L 1$ & Determinacy & $\begin{array}{l}\text { Comparative genomics/candidate gene } \\
\text { sequencing/linkage mapping }\end{array}$ & Mir et al. (2014) \\
\hline DLP & Drought & qRT-PCR & $\begin{array}{l}\text { Deeplanaik et al. } \\
(2013)\end{array}$
\end{tabular}

respectively, by using NGS-based approach (Singh et al. 2016). Seven genes such as CcHyPRP, CcCDR, CcCYP, CcMT1, DLP, APB, and $L T P 1$ were identified in pigeonpea from subtracted cDNA libraries among which transcriptional up-regulation of dehydrin-like protein $(D L P)$ was observed under drought response (Deeplanaik et al. 2013). In another study, seven genes (CcAP, CcFCA, CcFLD, CcFKF1, CcGI, CcTFL2, and CcTFL1) related to determinacy/flowering pattern in pigeonpea were isolated through a comparative genomics approach. Among these seven genes, two genes ( $C c G I$ and $C c T F L 1$ ) were genetically mapped using biparental mapping population and one gene (CCTFL1) was declared likely candidate for determinacy in pigeonpea by using candidate gene sequencing, comparative genomics, linkage-based QTL mapping, and expression analysis approaches (Mir et al. 2014).

\subsection{Identification of Genes Through Transcriptomics}

The traditional molecular mapping methods have been extensively used to map quantitative trait loci (QTL)/genes for traits of agronomical importance. However there use have been limited, due to time consumption, expensive and laborious procedures for marker development and validation. This resulted in advancement toward efficient, accurate, and cost-effective strategy of next-generation sequencing (NGS) technologies. NGS technologies have opened up wealth of opportunities for plant breeding and genetics studies in addition to de novo sequencing of crops. Transcriptome sequencing has increased the accessibility of genomic resources in pigeonpea. In pigeonpea, the first EST resource provides the transcriptomics for gene discovery and development of functional markers associated with Fusarium wilt and SMD (Raju et al. 2010). As root is the site of infection for Fusarium udum, therefore, cDNA libraries were constructed from root tissues to evaluate the transcriptional response after pathogen infection. Similarly for SMD, leaf is the primary site of infection and as such cDNA libraries were constructed from leaf tissues. A total of four pigeonpea genotypes namely 'ICPL 20102' (FW resistant), 'ICP 2376' (FW susceptible), 'ICP7035' (SMD-resistant), and 'TTB7' (SMD-susceptible) were used in this study. Another set of ESTs was generated from whole plant tissues of pigeonpea subjected to PEG/water deficit stress conditions (Priyanka et al. 2010). Two subtracted cDNA libraries were constructed from pigeonpea plants treated with $10 \%$ polyethylene glycol (PEG-6000). Among the various ESTs identified, three of the selected stress-responsive genes, viz. $C c H y P R P, C c C D R$, and $C c C Y P$ showed remarkable tolerance against multiple abiotic stresses in transgenic Arabidopsis. Kumar et al. (2015) analyzed the transcriptome of pigeonpea roots under 
Table 6.3 NGS platforms used for identification of transcripts/genes in pigeonpea

\begin{tabular}{l|l|l}
\hline NGS platform & Transcripts/unigenes & References \\
\hline 454FLX & 43,324 & Dutta et al. (2011) \\
\hline 454FLX and Illumina & 127,754 & Dubey et al. (2011) \\
\hline Illumina & - & Saxena et al. (2012) \\
\hline FLX/454 and Illumina & 21,434 & Kudapa et al. (2012) \\
\hline
\end{tabular}

water deficit by suppression subtractive hybridization ( $\mathrm{SSH})$. In this experiment, plants were grown at $-0.45 \mathrm{MPa}$ stress level by using PEG-6000 for SSH library construction. A comprehensive transcriptome assembly from more than 16 pigeonpea genotypes has been developed by using Sanger along with second-generation sequencing platforms (Illumina GA IIx and FLX/454) (Kudapa et al. 2012). The resultant transcriptome comprised of 21,434 transcript assembly contigs. This transcriptome referred as CcTAv2 was generated from ange of tissues and under various stress treatments given to the plants. CcTAv2 was mapped on the soybean genome as reference, and putative mapping positions of ISR markers (intron spanning regions) were predicted. A subset of ISR markers were validated in few parental genotypes for important economic traits that are important for pigeonpea improvement. CcTAv2 assembly can be used for gene identification and function, for development of molecular markers like SSRs, SNPs (Varshney et al. 2009). In general, transcriptome sequencing has increased the genomic resource availability in pigeonpea, which can be used for molecular breeding programs to develop elite cultivars of pigeonpea. Different sequencing platforms used to generate transcriptome assemblies in pigeonpea are summarized in Table 6.3.

\subsection{Genes Identified/Mapped Through Genome Sequencing}

Low genetic diversity among the cultivated pigeonpea genotypes has hindered the conventional breeding programs in this crop. Before 2006, almost no genomics resource of pigeonpea was available. Pigeonpea genomics initiative
(PGI) under the umbrella of Indo-US agricultural knowledge initiative (AKI) was started in late 2006 to enable genomics-assisted breeding in this crop. Later funding from the Generation Challenge Program (GCP) of the Consultative Group on International Agricultural Research (CGIAR) and by joining of additional collaborators across several institutes and countries has strengthened the initiative. Varshney et al. (2012a) used the Illumina GA and HiSeq 2000 sequencing platforms along with Sanger-based bacterial artificial chromosome (BAC) end sequencing to decode $605.78 \mathrm{Mb}(72.7 \%)$ of the 833.07 $\mathrm{Mb}$ pigeonpea genome. This represents the first genomic report of orphan legume crop 'pigeonpea' with 48,680 genes. Of the 48,680 genes, 266 were identified as ORFans (genes representing lineage specific pattern and with no sequence similarity in the genome or protein database) and 111 drought-responsive genes.

Another draft genome of the pigeonpea variety, 'Asha,' was completed by using 454 GS-FLX chemistry (Singh et al. 2012). This study identified 59,515 genes including 12, 511 transposable element-related genes. Among 47,004 protein-coding genes, 1213 were identified as disease resistance/defense response and 152 as abiotic stress tolerance genes. Availability of genome sequence has opened a wealth of opportunities for the improvement of pigeonpea. In pigeonpea, next-generation sequencing, sequencing-based bulked segregant analysis (Seq-BSA) was used to map resistance genes for FW and SMD. Two important genes namely C.cajan_01839 for SMD resistance and C.cajan_03203 for FW resistance have been reported in pigeonpea, whose introgression will be useful in molecular breeding of the crop (Singh et al. 2016). 


\subsection{Conclusion}

Gradual decline in soil water and increase in temperature will be the major challenges in near future for food production. Drought and hightemperature tolerant crops such as pigeonpea can be a choice to provide food security especially to the SAT regions of the world. Low genetic diversity and biotic stresses are the major bottleneck in pigeonpea production. However, significant progress has been made in the generation of vast genomics resources, transcriptomics, and whole genome sequencing. In addition, the availability of wild/cultivated germplasm, core/mini-core collections, biparental mapping populations, advanced breeding lines, released varieties has facilitated discovery of genes/QTLs in pigeonpea. Various approaches of gene discovery like QTL mapping, association mapping, candidate gene sequencing/analysis, transcriptomics, and whole genome sequencing have been employed successfully in this crop (Fig. 6.1). With the result promising genes/QTLs with major effect have become available for important targeted traits like flowering time, determinacy, fertility restoration (FR), Fusarium wilt (FW), and sterility mosaic disease (SMD). More sophisticated approaches like use of nested association mapping (NAM) and use of multi-parent advanced generation intercross populations (MAGIC) shall be used in future for high resolution/precision mapping of genes/QTLs for important traits in pigeonpea. The genes/QTLs already identified shall be validated in different genetic backgrounds before recommending them for marker-assisted selection (MAS) programs in pigeonpea. In addition to marker-assisted selection (MAS), other modern breeding approaches like marker-assisted recurrent selection (MARS) and genomic selection (GS) shall be used in pigeonpea for quick genetic gain.

\section{References}

Bohra A, Dubey A, Saxena RK, Penmetsa RV, Poornima KN, Kumar N, Farmer AD, Srivani G, Upadhyaya HD, Gothalwal R, Ramesh R et al (2011)
Analysis of BAC-end sequences (BESs) and development of BES-SSR markers for genetic mapping and hybrid purity assessment in pigeon pea (Cajanus spp.). BMC Plant Biol 11:56

Bohra A, Saxena RK, Gnanesh BN, Saxena KB, Byregowda M, Rathore A et al (2012) An intra-specific consensus genetic map of pigeon pea [Cajanus cajan (L.) Millspaugh] derived from six mapping populations. Theor Appl Genet 125:1325-1338

Buckler ES, Thornsberry JM (2002) Plant molecular diversity and applications to genomics. Curr Opin Plant Biol 5:107-111

Deeplanaik N, Kumaran RC, Venkatarangaiah K, Shivashankar SKH, Doddamani D, Telkar S (2013) Expression of drought responsive genes in pigeon pea and in silico comparison with soybean cDNA library. J Crop Sci Biotechnol 16:243-251

Dubey A, Farmer A, Schlueter J, Cannon SB, Abernathy B, Tuteja R et al (2011) Defining the transcriptome assembly and its use for genome dynamics and transcriptome profiling studies in pigeon pea (Cajanus cajan L.). DNA Res 18:153-164

Dutta S, Kumawat G, Singh BP, Gupta DK, Singh S, Dogra V, Gaikwad K, Sharma TR, Raje RS, Bandhopadhya TK, Datta S, Singh MN et al (2011) Development of genic-SSR markers by deep transcriptome sequencing in pigeon pea [Cajanus cajan (L.) Millspaugh]. BMC Plant Biol 11:17

Flint-Garcia SA, Thornsberry JM, Buckler ES (2003) Structure of linkage disequilibrium in plants. Annu Rev Plant Biol 54:357-374

Gnanesh BN, Bohra A, Sharma M, Byregowda M, Pande S, Wesley V et al (2011) Genetic mapping and quantitative trait locus analysis of resistance to sterility mosaic disease in pigeon pea [Cajanus cajan (L.) Millsp.]. Field Crops Res 123:53-61

Gupta PK, Rustgi S, Kulwal PL (2005) Linkage disequilibrium and association studies in higher plants: present status and future prospects. Plant Mol Biol 57:461-485

Gupta PK, Kulwal PL, Mir RR (2013) QTL mapping: methodology and applications in cereal breeding. In: Gupta PK, Varshney RK (eds) Cereal Genomics II. Springer, Netherlands, pp 275-318

Kotresh H, Fakrudin B, Punnuri SM, Rajkumar BK, Thudi M, Paramesh $\mathrm{H}$ et al (2006) Identification of two RAPD markers genetically linked to a recessive allele of a Fusarium wilt resistance gene in pigeon pea (Cajanus cajan L. Millsp.). Euphytica 149:113-120

Kudapa H, Bharti AK, Cannon SB, Farmer AD, Mulaosmanovic B, Kramer R et al (2012) A comprehensive transcriptome assembly of pigeon pea (Cajanus cajan L.) using Sanger and second-generation sequencing platforms. Mol Plant 5:1020-1028

Kumar R, Yadav S, Shrinivas, Kumar Srivastava A, Shitole V, Naik GR (2015) Transcriptome of pigeon pea roots under water deficit analyzed by suppression subtractive hybridization. J Agri Sci Technol 17:1333-1345 
Kumawat G, Raje RS, Bhutani S, Pal JK, Mithra ASVCR, Gaikwad K, Sharma TR, Singh NK (2012) Molecular mapping of QTLs for plant type and earliness traits in pigeon pea (Cajanus cajan L. Millsp.). BMC Genet 13:84

Mir RR, Zaman-Allah M, Sreenivasulu N, Trethowan R, Varshney RK (2012) Integrated genomics, physiology and breeding approaches for improving drought tolerance in crops. Theor Appl Genet 125:625-645

Mir RR, Saxena RK, Saxena KB, Upadhyaya HD, Kilian A, Cook DR et al (2013) Whole-genome scanning for mapping determinacy in pigeon pea (Cajanus spp.). Plant Breed 132:472-478

Mir RR, Kudapa H, Srikanth S, Saxena RK, Sharma A, Azam S et al (2014) Candidate gene analysis for determinacy in pigeon pea (Cajanus spp.). Theor Appl Genet 127:2663-2678

Mohar S, Narinder KG, Mukesh KR, Om PD, Dutta M et al (2014) Pigeon pea genetic resources and its utilization in India:current status and future prospects. J Plant Sci Res 1:107

Mula MG, Saxena KB (2010) Lifting the level of awareness on pigeon pea-a global perspective. International Crops Research Institute for the Semi-Arid Tropics (ICRISAT), Patancheru, India

Prasanthi L, Reddy BVB, Rekha Rani K, Naidu PH (2009) Molecular marker for screening Fusarium wilt resistance in pigeon pea [Cajanus cajan (L.) Millspaugh]. Legume Res 32:19-24

Priyanka B, Sekhar K, Sunita T, Reddy VD, Rao KV (2010) Characterization of expressed sequence tags (ESTs) of pigeon pea (Cajanus cajan L.) and functional validation of selected genes for abiotic stress tolerance in Arabidopsis thaliana. Mol Genet Genomics 283:273-287

Raju NL, Gnanesh BN, Lekha P, Jayashree B, Pande S, Hiremath PJ et al (2010) The first set of EST resource for gene discovery and marker development in pigeon pea (Cajanus cajan L.). BMC Plant Biol 10:1

Saxena KB, Ravikoti VJ, Sultana R (2010a) Quality nutrition through pigeon pea-a review. Health 2:1335-1344

Saxena RK, Prathima C, Saxena KB, Hoisington DA, Singh NK et al (2010b) Novel SSR markers for polymorphism detection in pigeon pea (Cajanus spp.). Plant Breed 129:142-148

Saxena RK, Cui X, Thakur V, Walter B, Close TJ, Varshney RK (2011) Single feature polymorphisms (SFPs) for drought tolerance in pigeon pea (Cajanus spp.). Funct Integr Genomics 11:651-657

Saxena RK, Penmetsa RV, Upadhyaya HD, Kumar A, Carrasquilla-Garcia N, Schlueter J et al (2012) Large-scale development of cost-effective single-nucleotide polymorphism marker assays for genetic mapping in pigeon pea and comparative mapping in legumes. DNA Res 19:449-461
Saxena RK, von Wettberg E, Upadhyaya HD, Sanchez V, Songok S, Saxena KB et al (2014) Genetic diversity and demographic history of Cajanus spp. illustrated from genome-wide SNPs. PLoS ONE 9:e88568

Saxena RK, Saxena KB, Pazhamala LT, Patel K, Parupalli S, Sameerkumar CV, Varshney RK (2015) Genomics for greater efficiency in pigeon pea hybrid breeding. Front Plant Sci 6:793

Sekhar K, Priyanka B, Reddy VD, Rao KV (2010) Isolation and characterization of a pigeon pea cyclophilin (CcCYP) gene, and its over-expression in Arabidopsis confers multiple abiotic stress tolerance. Plant, Cell Environ 33:1324-1338

Sharma M, Rathore A, Mangala UN, Ghosh R, Sharma S, Upadhyay HD et al (2012) New sources of resistance to Fusarium wilt and sterility mosaic disease in a mini-core collection of pigeon pea germplasm. Eur $\mathbf{J}$ Plant Pathol 133:707-714

Singh NK, Gupta DK, Jayaswal PK, Mahato AK, Dutta S, Singh S et al (2012) The first draft of the pigeon pea genome sequence. J Plant Biochem Biotechnol 21:98112

Singh AK, Rai VP, Chand R, Singh RP, Singh MN (2013) Genetic diversity studies and identification of SSR markers associated with Fusarium wilt (Fusarium udum) resistance in cultivated pigeon pea (Cajanus cajan). J Genet 92:273-280

Singh VK, Khan AW, Saxena RK, Kumar V, Kale SM, Sinha P, et al. (2016) Next-generation sequencing for identification of candidate genes for Fusarium wilt and sterility mosaic disease in pigeon pea (Cajanus cajan). Plant Biotechnol J 14:1183-1194

Smartt J (1990) Grain legumes: evaluation and genetic resources. Cambridge University Press, Cambridge, UK

Tamirisa S, Vudem DR, Khareedu VR (2014) Overexpression of pigeon pea stress-induced cold and drought regulatory gene $(C c C D R)$ confers drought, salt, and cold tolerance in Arabidopsis. J Exp Bot 65:4769-4781

Tanksley SD, Nelson JC (1996) Advanced backcross QTL analysis: a method for the simultaneous discovery and transfer of valuable QTLs from unadapted germplasm into elite breeding lines. Theor Appl Genet 92:191-203

Van Der Maesen LJG (1990) Pigeon pea: Origin, history, evolution and taxonomy. In: Nene YL, Hall SD, Sheila VK (eds) The Pigeon pea. CAB International, Wallingford, UK, pp 15-46

Varshney RK, Nayak SN, May GD, Jackson SA (2009) Next generation sequencing technologies and their implications for crop genetics and breeding. Trends Biotechnol 27:522-530

Varshney RK, Penmetsa RV, Dutta S, Kulwal PL, Saxena RK, Datta S et al (2010a) pigeon pea genomics initiative (PGI): an international effort to improve crop 
productivity of pigeon pea (Cajanus cajan L.). Mol Breed 26:393-408

Varshney RK, Thundi M, May GD, Jackson SA (2010b) Legume genomics and breeding. Plant Breed Rev 33:257-304

Varshney RK, Chen W, Li Y, Bharti AK, Saxena RK et al (2012a) Draft genome sequence of Pigeon pea (Cajanus cajan), an orphan legume crop of resource-poor farmer. Nat Biotechnol 30:83-89

Varshney RK, Kudapa H, Roorkiwal M, Thudi M, Pandey MK, Saxena RK et al (2012b) Advances in genomics research and molecular breeding applications in SAT legume crops by using next generation sequencing and high-throughput genotyping technologies. J Biosci 37:811-820
Vavilov (1928) Geographische Genzentren unserer Kulturpflanzen; Verhandlungen des V Internationalen Kongresses fur Vererbungswissenschaft. Berlin, Germany 1927: 342-369

Yang S, Pang W, Harper J, Carling J, Wenzl P, Huttner E et al (2006) Low level of genetic diversity in cultivated pigeon pea compared to its wild relatives is revealed by diversity arrays technology (DArT). Theor Appl Genet 113:585-595

Yang S, Saxena RK, Kulwal PL, Ash GJ, Dubey A, Harper JD et al (2011) First genetic map of pigeon pea based on diversity array technology (DArT) markers. J Genet 90:103-109

Yu J, Buckler ES (2006) Genetic association mapping and genome organization of maize. Curr Opin Biotechnol 17:155-160 